\title{
Recuperar el mandamiento de la filadelfía del libro de Hebreos para una nueva eclesiología"
}

\author{
Elizabeth Gareca Gareca*
}

Recepción: 30 de agosto de 2018 • Aprobación: 22 de septiembre de 2018

\section{Resumen}

El libro de Hebreos desarrolla una cristología alrededor de la figura de Jesús y de una comunidad firme en su fe cristiana, a pesar de los riesgos que suponía. Proporciona el título de Sumo Sacerdote a Jesús, desde una nueva genealogía, Melquisedec. El verdadero sacerdocio fiel al mensaje cristiano es capaz de testimoniar al Dios vivo, asumir la realidad humana y tomar distancia de la ritualidad sacrificial y banal $(\mathrm{Hb} 10,1)$. Ya el Documento de Medellín (1968) tiene una vasta recomendación a los sacerdotes de América Latina sobre su servicio en misión permanente. Sin embargo, no ha sido suficiente y hoy tenemos una Iglesia en crisis con sus vocaciones sacerdotales y con su feligresía. Como cristiana y laica, propongo repensar el sacerdocio relativizando algunas exigencias que resultan anacrónicas y soñando con una Iglesia que encarne un discipulado de iguales.

Palabras clave: sacerdocio, laicado, mujeres, Iglesia, discipulado de iguales.

* Artículo producto de una tesis de maestría para la Universidad Nacional de Costa Rica en convenio con la Universidad Bíblica Latinoamericana. Fue presentado en el Primer Congreso Internacional de Teología Latinoamericana y del Caribe: 50 años de Medellín: Iglesia y signos de los tiempos, desarrollado en la Universidad Santo Tomás entre el 16 y el 19 de octubre de 2018. Citar como: Gareca Gareca, E. (2018). Recuperar el mandamiento de la filadelfía del libro de Hebreos para una nueva eclesiología. Albertus Magnus, IX(2), 51-70. Doi: https://doi. org/10.153322/5005413.5111.

* Universidad Salesiana, Bolivia. Correo electrónico: elizabeth.gareca@usalesiana.edu.bo 


\title{
Retrieving the Philadelphia commandment from the Hebrews text for a new ecclesiology
}

\begin{abstract}
Hebrews develops a Christology around the figure of Jesus and a community that is firm in its Christian faith, despite the risks involved. It provides the title of "high priest" to Jesus, from a new genealogy, Melchizedek. The true priesthood faithful to the Christian message is capable of witnessing to the living God, assuming human reality and taking distant from the sacrificial and banal rituality $(10,1)$. The Document of Medellin (1968) has a vast recommendation to the priests of Latin America about their service in permanent mission. However, it has not been enough and today we have a church in crisis with its priestly vocations and with its parishioners. As a Christian and lay I propose to rethink the priesthood by relativizing some demands that are anachronistic and dreaming of a church that incarnates a discipleship of equals
\end{abstract}

Keywords: priesthood, laity; women, Church, discipleship of equals.

\section{Recuperando o mandamento de filadélfia do texto de Hebreus para uma nova eclesiologia}

\section{Resumo}

Hebreus desenvolve uma cristologia em torno da figura de Jesus e de uma comunidade que é firme em sua fé cristã, apesar dos riscos envolvidos. Ele fornece o título de "Sumo Sacerdote" a Jesus, a partir de uma nova genealogia, Melquisedeque. O verdadeiro sacerdócio fiel à mensagem cristã é capaz de testemunhar ao Deus vivo, assumindo a realidade humana e distanciando-se da ritualidade sacrificial e banal $(10,1)$. Já o Documento do Medellin (1968) tem uma vasta recomendação aos sacerdotes da América Latina sobre seu serviço em missão permanente. No entanto, isso não tem sido suficiente e hoje temos uma igreja em crise com suas vocações sacerdotais e com seus paroquianos. Como cristão e leigo, proponho repensar o sacerdócio relativizando algumas exigências que são anacrônicas e sonhando com uma igreja que encarna um discipulado de iguais.

Palabras-chave: sacerdócio, leigos, mulheres, Igreja, discipulado de iguais. 


\section{Introducción}

El libro de Hebreos, que más cualifica como sermón u homilía que como epístola, desarrolla una cristología alrededor de la figura de Jesús como sacerdote. Esto resulta llamativo dentro de los escritos del Nuevo Testamento, por lo cual se indagará sucintamente este escrito. El verdadero sacerdocio fiel al mensaje cristiano es capaz de testimoniar al Dios vivo, asumir la realidad humana y tomar distancia de la ritualidad sacrificial y banal que representaba la Ley y el Templo $(\mathrm{Hb} 10,1)$. Por eso creo que quien escribe este texto hace una ruptura profunda entre un culto sacerdotal tradicional judío y basado en la Ley, y un nuevo culto cristiano basado en nuevas relaciones humanas, anclado en la filadelfía $(\mathrm{Hb} \mathrm{13}, 1) .{ }^{1}$

La Iglesia del siglo XXI se ve diezmada en sus vocaciones sacerdotales, situación que debe preocupar a todo laico que se sienta parte de esta Iglesia y, al mismo tiempo, a todo el contexto clerical. Ya el Documento de Medellín (1968) tiene una vasta recomendación a los sacerdotes de América Latina sobre cómo asumir su servicio en misión permanente hacia al pueblo sencillo. La historia posterior a Medellín demuestra que las propuestas fueron insuficientes para construir una eclesiología de la liberación o los postulados no lograron su aplicación dentro del aggiornamento del Concilio Vaticano II, ante la Tradición y la jerarquía. En este periodo de recepción de Medellín, la dupla laicado y clero tuvieron encuentros y desencuentros. Ahora ambas realidades se encuentran distanciadas y con una tendencia al conservadurismo de una jerarquía que, en muchos casos, posee el poder eclesial y ubica a los laicos en espacios de inferioridad, bajo nuevas formas de evangelización o colonización modernas y sutiles.

En este contexto, se va a recuperar la propuesta de la cristología sacerdotal presente en Hebreos, en un planteamiento radicalmente distinto para asumir este servicio hacia el Pueblo de Dios. Como cristiana laica, me siento corresponsable (Benedicto XVI, 2012), aunque no sé si debería, puesto que nuestra voz no cuenta en las esferas de la Iglesia donde se toman decisiones. De todas formas las mujeres también podemos opinar sobre la urgencia de vivir una nueva eclesiología católica o universal. El sacerdocio que responda a este desafío debe partir del servicio y de asumir una vocación de entrega total hacia el Pueblo de Dios, conociendo que el contexto de globalización moderno es primordialmente laico. La jerarquía eclesial debe pasar del "poder sobre" el Pueblo de Dios, al "poder para

1 Palabra griega clave del texto bíblico del capítulo 13 de Hebreos; más adelante se profundiza en su significado. Preliminarmente, se puede decir que es una caridad que nace en las entrañas por el prójimo. 
el servicio". Ser testigos de esta "pascua" solo será posible con una Iglesia que tenga sensibilidad social y sea, al mismo tiempo, intuición evangélica.

Creo que una Iglesia laica es posible aquí y ahora; una Iglesia democrática y participativa; una Iglesia que comparta con igualdad y equidad con la mitad de la población que hasta hoy se ha negado a visibilizar y dialogar: las mujeres. Los argumentos que tanto Lumen gentium como el Documento de Medellín han sostenido para relegar a la mujer a un papel secundario ya no son sostenibles, de ahí que se propone retomar el tema frente a trabajar una reforma que nazca en nuestro continente y se haga escuchar también en el Vaticano.

Para desarrollar este tema, voy a comenzar haciendo un recuento del periodo pos-Medellín desde mi experiencia. Después uso el texto bíblico de Hebreos en un acercamiento sincrónico y con una exégesis sucinta, que se complementa con una hermenéutica en clave eclesial. La tercera parte es una propuesta hacia una nueva Iglesia capaz de convertirse en un "discipulado de iguales", 2 entendiendo esto como una utopía de muchas mujeres pero apostando por su inclusión en la agenda de la Iglesia latinoamericana y caribeña.

\section{Una mirada crítica del periodo pos-Medellín}

La Iglesia es consciente de un éxodo masivo de personas dentro de su feligresía, lo cual puede deberse a una amplia lista de causas. Distamos mucho de vivir una primavera eclesial como producto de la Conferencia de Medellín. Más bien, existe una tendencia contraria al aggiornamento que proponía Juan XXIII, un regreso sutil hacia las líneas más conservadoras del clero y el laicado. Medellín fue un hecho eclesial por demás importante, pues significaba la aplicación creativa, contextualizada y situada de los documentos más importantes que fraguaron el Vaticano II. Por el contrario, el periodo siguiente a Medellín ha sido desesperanzador para toda la Iglesia.

Por otro lado, el mundo ha cambiado drástica y aceleradamente en estos cincuenta años. La laicidad se ha constituido en un valor altamente reclamado en un mundo plural, diverso y posmoderno. Desde la filosofía, la ética, la sociología y otras ciencias afines, se han dado algunas respuestas a esta nueva situación de la sociedad contemporánea. De ahí que, en el continente americano, se viva una tendencia a la descolonización, promovida por las llamadas epistemologías

2 Propuesta realizada por Elisabeth Schussler Fiorenza sobre una Iglesia democrática conformada por sujetos plenos, que comparten una participación igualitaria. 
del sur. Dichas epistemologías implicaron procesos de deconstrucción de todo cuanto significó la evangelización anclada con la colonización en un sistema de poder y opresión. La conciencia y la identificación de la Iglesia como parte de la colonización también han jugado en contra. El nuevo sujeto que emerge ante esta reflexión es capaz de identificar en su ADN histórico: la colonialidad. En consecuencia, se trabaja en la propia deconstrucción de sentidos, para desenmascarar los ámbitos de poder y proponer nuevas formas de vida con una mirada integral, holística y laica. Existe un regreso a las religiosidades ancestrales y otras formas de espiritualidad, a veces lejos de las religiones institucionalizadas, como el cristianismo.

En los últimos treinta años, todos los países latinoamericanos y caribeños, excepto Costa Rica, se crearon como laicos junto con otros países que ya se habían iniciado en la laicidad a finales del siglo XIX. Esto significó el impulso de la democracia, pues permitió la inclusión de la libertad religiosa en la Constitución y en las leyes nacionales. Aquí se encuentra otro factor relativamente nuevo que se vivió después de la Conferencia de Medellín y frente al cual la Iglesia no hizo una lectura adecuada y, consecuentemente, no contribuyó a su desarrollo. La Iglesia y los Estados mantienen todavía una alianza muy fuerte, lo cual es un peligro en un continente en el que la injusticia se pandea a gusto.

Lo positivo que se vivió a partir de Medellín merece también ser exaltado. El evento eclesial proveyó de nuevos aires a las liturgias y en la forma de estar presente en el mundo. A partir de ello, hubo una apropiación de la Biblia por parte del pueblo y la apertura a la libertad de su interpretación. Nos hemos congregado en las comunidades eclesiales de base (CEB) que pulularon en las décadas de 1970 y 1980 con fuertes compromisos políticos y religiosos. Se aplicó la metodología del ver-juzgar-actuar con éxito en comunidades cercadas por la represión y las dictaduras. También fuimos testigos de la organización de grupos y movimientos laicales que poblaron los templos y las parroquias con gran fervor religioso.

La Iglesia emprendió un proceso de inculturación en nuestro continente. En algunos casos, se dejó evangelizar por las culturas ancestrales, rescatando los valores éticos que cada una de las culturas encierra dentro de sí misma. Cambió el discurso tradicional y ortodoxo, incorporó elementos culturales a las liturgias y emprendió una evangelización de acogimiento con las nuevas formas religiosas que se descubrían de mejor forma en cuanto más se adentraba en sus vivencias. Esto fue una experiencia no contemplada en Medellín, pero que fue parte del contexto posterior que incorporó, generalmente, con corazón abierto.

En tiempos de dictadura y represión política en nuestro continente, vimos una Iglesia practicando verdaderamente la opción por los pobres, por el pueblo 
oprimido. Hemos llorado en todos los países nuestros mártires tanto del clero como laicos; el poder no les perdonó su coherencia cristiana. La Iglesia tuvo momentos de lucidez y debemos resaltarlos. Los escritos que se originaron dentro el paraguas de la liberación inspiraron a mucha gente de nuestro continente y del mundo entero. La liberación era la utopía.

Finalmente, la Iglesia, tras Medellín, ha continuado siendo una Iglesia patriarcal que no ha dado buenas señales a las mujeres que luchan por la justicia de género, ha rechazado permanentemente todos los pedidos de las mujeres de tener una Iglesia más democrática y participativa para ellas, incluso para las que desean acceder al sacerdocio. Este rechazo fue con argumentos anacrónicos e inoportunos. Somos la mitad de la población y en ámbitos religiosos no tenemos voz propia ni mayoría de edad, sino que es el clero el que sigue pensando por nosotras; somos objeto de reflexión: ¿no será hora de convertirnos en sujetos?

\section{Estudio bíblico}

Es claro que cuando se lee el libro de Hebreos se encuentra un vocabulario propio y distinto de los demás escritos. Por ejemplo, es el único libro del Nuevo Testamento que usa el título de Sumo Sacerdote para Jesús. Sin duda, el libro pareciera ser una pieza literaria atípica. De ahí parte la necesidad de un estudio exegético basado en este libro bíblico. Para profundizar en la exégesis, identificaremos la estructura del libro y el género literario al cual pertenece. A partir de estos parámetros, se usará el método narrativo y retórico que se sirve de determinados elementos: lugar, tiempo, tipo de relato, personajes, trama, relación autor-destinatarios, entre otros, para dilucidar el mensaje de este texto bíblico.

Aparentemente, se trata de un texto homilético del primer siglo. La datación también es ambigua según el autor que se lea, sin embargo, hay una tendencia a ubicarlo antes de la destrucción del Templo en 70, por todas las referencias al culto que tiene el texto $(\mathrm{Hb} 10,1-3)$. Me adscribo a una datación temprana. Se desconoce su autor y la comunidad destinataria. Un dato importante de su autor es que, conforme avanzan los estudios exegéticos bíblicos, más se descarta la autoría de Pablo, al cual endosaban este escrito como "epístola". Hoppin (2009) publica un libro titulado La carta de Priscila en el que alude a varias sospechas de tipo literario, histórico y antropológico, para afirmar que este escrito pertenece a Priscila y que, por tanto, fue escrito desde Roma y destinado a la comunidad de 
Éfeso. No ahondaré demasiado en la autoría, pues en varios libros, como en el de Manzi (2005), se apoya la tesis de la autoría a Apolo.

El género literario de Hebreos responde más adecuadamente a una vasta homilía sinagogal escrita muy tempranamente quizá con motivo de alguna celebración especial y que después alguien decide cristianizar a partir de la figura de Jesús como Sacerdote. Con todo, siempre se la catalogó de carta o epístola, porque tiene una introducción que menciona saludos a la comunidad destinataria y una despedida, quizá añadida muy posteriormente. El género literario, entonces, corresponde a una homilía con adecuación epistolar posterior.

Esta hipótesis es posible por las abundantes citas literarias del Antiguo Testamento que contiene. Además, sigue un orden litúrgico: una cita de la Torá, concretamente del Génesis (14) y el Deuteronomio (32, 35) (Hb 10, 30-31), otra lectura sapiencial de los Salmos $104(\mathrm{Hb} 7-9)$ y 95 (distribuidas por todo el libro) y algunas lecturas proféticas de Isaías $(8,17-18)(\mathrm{Hb} 2,12 b-13)$ y Jeremías $(31,31-34)$ ( $\mathrm{Hb} 8,8 \mathrm{~b}-12)$. Al usar las citas bíblicas, siempre antecede o continúa una explicación y ampliación desde la experiencia cristológica (Hb 3, 7-19; 5, 1-6).

\section{Relectura bíblica}

Mi acercamiento al texto se cimienta en la estructura del escrito bíblico. Dicha estructura tiene una estrecha relación con el género literario, debido a que las temáticas que desarrolla la homilía determinan las unidades del texto. Si el género literario es una homilía adecuada y compartida a manera de epístola con una comunidad, su autor abarca varias temáticas interrelacionadas, en las que su centro es Jesús, el Cristo. En esta investigación, se hace una propuesta de estructura, basada en cuatro temáticas que aborda el texto:

- Soteriología cristológica $(\mathrm{Hb} 1,1-4,14)$

- Cristología sacerdotal ( $\mathrm{Hb} 4,15-10,31)$

- $\quad$ Anamnesis desde la fe (Hb 10, 32-12, 29)

- $\quad$ Vida cristiana $(\mathrm{Hb} 13,1-13,25)$

\subsection{Soteriología cristológica}

La primera parte de la estructura que propongo está dedicada a la soteriología cristológica, que es una descripción profunda de cómo Cristo, salvador de la humanidad, está ubicado por encima de los ángeles, lo cual es citado en el texto 
( $\mathrm{Hb} 1,4-13 ; 2,2-16)$. Por eso, se cree que es un texto en diálogo con los esenios, ${ }^{3}$ puesto que en sus escritos se menciona a los ángeles como seres originados en Dios y con poderes. En este sentido, si existe un afán de quien escribe de restar importancia a los ángeles, es porque seguramente se les consideraba seres superiores y divinos en ese contexto, de ahí que la soteriología desarrollada en esta parte contiene el esfuerzo de afirmar que son los ángeles quienes están al servicio del Cristo ( $\mathrm{Hb} 1,5,14 ; 2,5)$. Por ejemplo: "Pero a aquel que fue hecho inferior a los ángeles por un poco, a Jesús, le vemos coronado de gloria y honor por haber padecido la muerte, pues por la gracia de Dios gustó la muerte para bien de todos" (Hb 2, 9).

Hablando de salvación propiamente dicha, encontramos esta muestra: "De hecho convenía que Dios, fin del universo y creador de todo, proponiéndose conducir muchos hijos a la gloria, al pionero de su salvación lo consumara por el sufrimiento, pues el consagrante y los consagrados son todos del mismo linaje" (Hb 2, 10-11). Es una soteriología basada en la corporalidad de Jesús, puesto que se hizo humano $(\mathrm{Hb} 2,14)$ para procurar la salvación de todos. Mediante Jesús, quienes creen participan de este linaje salvífico, solo con la condición de una fe firme $(\mathrm{Hb} 4,3)$. El cierre de esta sección es totalmente sugerente a una comunidad perseguida y amenazada en sus convicciones de fe:

Así que no hay creatura que esté oculta a Dios. Todo está al desnudo $\mathrm{y}$ al descubierto a los ojos de aquel a quien hemos de rendir cuentas. $Y$ ya que tenemos en Jesús, el Hijo de Dios, un Sumo Sacerdote eminente que ha penetrado en los cielos (¡no solo en el santo sanctorum!), mantengámonos firmes en la fe que profesamos. ( $\mathrm{Hb} 4,13-14)$

Este cierre es una alusión a la omnipotencia de Dios para una comunidad que sufre por los poderes opresivos políticos y religiosos de su contexto. Viven en constante amenaza de muerte y es importante recordarles quién es en última instancia a quién le deben su existencia, Dios. De ahí que es importante cuidar sus conductas y sus éticas. Recordemos que esta idea la mantienen por su cosmovisión hebrea que creían que el cielo es el trono de Dios.

3 Grupo judío contemporáneo al judaísmo del tiempo de Jesús que vivía en ascesis y en aislamiento. En 1946, se descubren los rollos del mar Muerto, los mismos que arrojan más luces sobre sus vivencias a través de sus escritos. 


\subsection{Cristología sacerdotal}

El desarrollo del título de Sumo Sacerdote que se le da a Jesús puede ser un intento de entablar un diálogo con el grupo judío esenio (Hoppin, 2009), el cual esperaba un mesías de genealogía sacerdotal de la misma línea que Melquisedec y no tanto como "rey davídico", procedente de la línea profética judía. Hebreos afirma que Cristo es Sumo Sacerdote de la genealogía de Melquisedec (Gn 14,18$20)$, rey de la justicia y la paz, misterioso rey y sacerdote ( $\mathrm{Hb} 5,6-11 ; 6,20 ; 7,28)$.

En esta sección, se puede identificar un pensamiento diferente del de Pablo, quien comienza judío y termina como judío, sin consumar una ruptura real con el judaísmo de su época. Quien sea el autor de este escrito tiene una fuerte crítica a la función que desempeñaba el culto, la Ley y los sacerdotes que componían el judaísmo. En mi criterio, es una cristología que rompe con el modelo judaico religioso y propone uno nuevo desde Cristo. Ese nuevo sacerdocio que propone el texto solo puede ser posible mediante la figura de Melquisedec (7, 1-10), el cual simplemente no tenía genealogía sacerdotal, sino que ni siquiera era del mismo pueblo $(7,6)$ : ¡era un sacerdote extranjero! Si este sacerdote extranjero fue capaz de bendecir a Abraham, considerado máximo patriarca de la fe del judaísmo, resulta paradójico ubicar a Melquisedec como superior a Abraham, pues quien bendice se ubica como superior al bendecido.

Esta mención de Melquisedec nos permite pensar en una apertura étnica y cultural más allá de las fronteras judías, igual que la misión de Jesús. Melquisedec goza de un sacerdocio eterno en la memoria de la tradición, pues, como se desconoce su muerte, está vivo para el autor. Por eso, a partir de $\mathrm{Hb} \mathrm{7,11}$, el autor rompe con su propia identidad judaica. Esto es, a mi entender, una paradoja con el nombre del libro. Desde aquí comienza a desarrollar por qué existe ineficacia del sacerdocio antiguo o judaico frente al nuevo sacerdocio de Cristo. Esta sección abarca hasta el $\mathrm{Hb} 10,18$, y son bastante amplios los argumentos que expone. Entre las principales causas de la ineficacia, podemos rescatar (tabla 1):

Tabla 1. Estudio del texto

\begin{tabular}{|l|l|}
\hline \multicolumn{1}{|c|}{ Sacerdocio levítico } & \multicolumn{1}{c|}{ Nuevo sacerdocio de Cristo } \\
\hline Proviene de la tribu de Leví (Hb 7, 5). & Proviene de Melquisedec (Hb 6, 20). \\
\hline $\begin{array}{l}\text { Pertenece a la tribu destinada al sacerdocio, Leví, } \\
\text { son quienes cobran los diezmos del pueblo (Hb } \\
7,5) .\end{array}$ & $\begin{array}{l}\text { Melquisedec no tiene genealogía levítica o } \\
\text { sacerdotal, se desconoce su procedencia y su } \\
\text { final (Hb 7, 3). } \\
\text { Jesús pertenece a la tribu de Judá, no destinada } \\
\text { al sacerdocio (Hb 7, 14). }\end{array}$ \\
\hline
\end{tabular}




\begin{tabular}{|c|c|}
\hline Sacerdocio levítico & Nuevo sacerdocio de Cristo \\
\hline $\begin{array}{l}\text { No lleva a la perfección }(\mathrm{Hb} 7,11) \text { ni ese } \\
\text { sacerdocio ni la Ley }(\mathrm{Hb} 7,12) \text {; se ciñe a una ley } \\
\text { meramente humana }(\mathrm{Hb} 7,16) \text {. }\end{array}$ & $\begin{array}{l}\text { No obedece a leyes terrenas, sino a la vida } \\
\text { indestructible }(\mathrm{Hb} 7,16) \text {. } \\
\text { Jesús es un sacerdote para la eternidad, perfecto } \\
\text { y santo para siempre }(\mathrm{Hb} 7,17) \text {. }\end{array}$ \\
\hline $\begin{array}{l}\text { El sacerdocio levítico no gozaba del juramento } \\
(\mathrm{Hb} 7,20) \text {. Juramento como compromiso de Dios. }\end{array}$ & $\begin{array}{l}\text { Está mediado por el juramento de Dios ( } \mathrm{Hb} 7 \text {, } \\
21 \mathrm{~b}) \text {. }\end{array}$ \\
\hline $\begin{array}{l}\text { Es finito porque la muerte es inevitable para ellos } \\
(\mathrm{Hb} 7,23) \text {. }\end{array}$ & $\begin{array}{l}\text { Jesús es un Sumo Sacerdote para siempre ( } \mathrm{Hb} \\
7,24) \text {. }\end{array}$ \\
\hline $\begin{array}{l}\text { El sacerdocio levítico debe ofrecer cada día } \\
\text { sacrificios por sus propios pecados (Hb 7, 27). }\end{array}$ & $\begin{array}{l}\text { Jesús no necesita ofrecer sacrificios por sus } \\
\text { pecados porque es santo y perfecto }(\mathrm{Hb} 7,27) \text {. }\end{array}$ \\
\hline $\begin{array}{l}\text { La Ley constituye sumos sacerdotes frágiles ( } \mathrm{Hb} \\
7,28 \mathrm{a}) \text {. }\end{array}$ & $\begin{array}{l}\text { Jesús es el Hijo de Dios, perfecto para siempre } \\
\text { (Hb 7, 28b). }\end{array}$ \\
\hline $\begin{array}{l}\text { Tienen su puesto en el santuario, en las tiendas, } \\
\text { en el templo, en lugares construidos por } \\
\text { humanos }(\mathrm{Hb} 8,2) \text {. }\end{array}$ & $\begin{array}{l}\text { Jesús es sentado en el mismo trono de Dios (Hb } \\
8,2-6) \text {. }\end{array}$ \\
\hline $\begin{array}{l}\text { El culto es la sombra de las “cosas celestiales" en } \\
\text { lugar terrenal }(\mathrm{Hb} 8,5) \text {. }\end{array}$ & $\begin{array}{l}\text { Jesús realiza el “culto celestial” en la tienda } \\
\text { erigida por el Señor }(\mathrm{Hb} 8,2) \text {. }\end{array}$ \\
\hline Pertenece a la primera Alianza (Hb 8, 7-8). & $\begin{array}{l}\text { El sacerdocio de Cristo es signo de la nueva } \\
\text { Alianza }(\mathrm{Hb} 8,13) \text {. }\end{array}$ \\
\hline $\begin{array}{l}\text { El sacerdocio levítico a punto de desaparecer }(\mathrm{Hb} \\
8,13) \text {. }\end{array}$ & $\begin{array}{l}\text { Mediante el sacerdocio de Cristo los creyentes } \\
\text { son consagrados para siempre }(\mathrm{Hb} 10,14) \text {. ¡Ya } \\
\text { no necesitamos de más sacrificios ni ofrendas! } \\
\text { (Hb 10, 18). }\end{array}$ \\
\hline $\begin{array}{l}\text { Necesita víctimas y sacrificios diarios y anuales } \\
(\mathrm{Hb} 9,25,27) \text {. }\end{array}$ & $\begin{array}{l}\text { Cristo se ofrece a sí mismo como víctima } \\
\text { perfecta }(\mathrm{Hb} 9,14) .\end{array}$ \\
\hline $\begin{array}{l}\text { Requiere ofrecer sacrificios una vez al año ( } \mathrm{Hb} 9 \text {, } \\
\text { 25) por los pecados de los sumos sacerdotes y } \\
\text { por los del pueblo }(\mathrm{Hb} 9,27) \text {. }\end{array}$ & $\begin{array}{l}\text { Solo una vez para siempre, para destruir el } \\
\text { pecado }(\mathrm{Hb} 9,26) \text {. }\end{array}$ \\
\hline
\end{tabular}

Fuente: Elaboración propia.

Las diferencias entre los dos sacerdocios, el legal levítico y el cristológico, son profundas para su autor. En la última parte del capítulo 10, se encuentran algunas recomendaciones a los destinatarios que guardan relación con todo el desarrollo anterior:

Mantengamos firme la esperanza que profesamos, porque fiel es el que hizo la promesa. Preocupémonos los unos por los otros, a fin de estimularnos al amor y a las buenas obras. No dejemos de congregarnos, como acostumbran hacerlo algunos, sino animémonos unos a otros, y con mayor razón ahora que vemos que aquel día se acerca. ( $\mathrm{Hb} 10,23-25)$ 
Dadas estas recomendaciones, podemos extrapolar que había cansancio, falta de ánimo y esperanza, y quizá una fuga de fieles de las comunidades. Es una invitación a mantenerse unidos y practicando la ritualidad de las primeras comunidades ( $\mathrm{Hb} 6,1 b-2)$. Esta sección es central, a mi entender, respecto de la inquietud de quien escribe este libro. Muestra una profunda preocupación por la sostenibilidad de la comunidad destinataria, les recuerda dónde radica la esperanza cristiana: Jesús mismo. Les insta a practicar las buenas obras y a vivir en mutuo consuelo ante las adversidades que padecían.

\subsection{Anamnesis desde la fe}

Esta sección comienza en $\mathrm{Hb}$ 10, 32: "recuerden aquellos primeros tiempos en los que, después de haber sido iluminados, soportaron un combate tan grande y doloroso". Hacer anamnesis es traer la historia pasada al presente, revivirla en la memoria, hacerla pasar nuevamente por el corazón. En esta sección, quien escribe se dedicará a recordar a su audiencia la historia pasada, para enfrentar un presente desolador. Esta anamnesis comienza citando a los antepasados que más fe tuvieron para enfrentar contrariedades de la vida y supieron encontrar siempre el camino de Dios.

Son personajes que se convierten en paradigmas en tiempos de sufrimiento. Ellos marcaron la historia de salvación o liberación. A partir de $\mathrm{Hb} 11,32$, detalla las proezas realizadas en nombre de la fe en el Dios vivo todos ellos. Esta anamnesis termina, como es de suponer, en Jesús $(\mathrm{Hb} 12,2)$ como paradigma de fe y entrega. Recuperar las enseñanzas ancestrales es importante, pero pensar en las enseñanzas que vienen de Dios es indispensable para la santidad que persigue la comunidad cristiana destinataria $(\mathrm{Hb} 12,10)$. Es posible enfrentar el presente desde la historia pasada y desde la guía que viene de Dios.

Qué elocuente discurso dedicado a hacer memoria e instar a su audiencia a practicar la "doctrina de la justicia". Lamentablemente, el contexto patriarcal del texto no permite recuperar la memoria a muchas mujeres que aportaron en la historia de liberación. Por ejemplo, Sara es citada en $\mathrm{Hb} 11,11$ por su poder de engendrar a todo un pueblo a partir de Isaac y Rajab en $\mathrm{Hb} 11,31$ realzada por su participación en la lucha contra los enemigos de Israel. Aunque solo dos son mencionadas en esta anamnesis, muchas más participaron pariendo a los grandes héroes, produciendo los frutos de la tierra, alimentando generaciones, cuidando de los ancestros, en fin, una constelación presente en el blanco del texto que también debemos resaltar. 
También hoy requerimos recordar a las mujeres que aportaron en la salvación o liberación histórica de la cristiandad. Los estudios críticos e históricos cada vez remarcan más su participación. La Iglesia es la que pierde cuando nos relegan a un papel secundario e invisible. Se ha desprovisto de una mirada intuitiva y misericordiosa, acorde con la coherencia evangélica que requiere el mundo de hoy. Dios señala un nuevo día, un nuevo hoy, diciendo mucho tiempo después, por medio de David, estas palabras: "si escuchan hoy su voz no endurezcan sus corazones" ( $\mathrm{Hb} 4,7)$. Esas palabras de salvación también pueden materializarse mediante la voz de las mujeres. ¡Dios no habla solo por medio de varones!

\subsection{Vida cristiana}

La vasta lista de recomendaciones en la parte final es la coronación de un discurso elocuente y retórico que busca despertar la conciencia de su audiencia, para conminarles a vivir auténticamente su fe, sin desmayar y con la seguridad de una recompensa de Dios. Nos ocuparemos solo de $\mathrm{Hb} 13,1-19$, y dejaremos por fuera de nuestro análisis la última parte de despedida ( $\mathrm{Hb} 13,20-25)$, que, coincidiendo con la mayoría de los autores, creo que es un añadido posterior.

En esta sección, encontramos una especie de despedida o un cierre de este libro, con un mensaje profundo: "Permanezcan siempre en el amor fraterno. No se olviden de la hospitalidad; gracias a ella hospedaron algunos, sin saberlo, a ángeles. Acuérdense de los presos, como si estuvierais con ellos encarcelados, y de los maltratados, pensando que también vosotros tenéis un cuerpo" ( $\mathrm{Hb} 13,1-2)$.

Una palabra griega usada al comienzo de esta sección es filadelfía $(\mathrm{Hb} 13$, 1). Puede tener varias traducciones: "amor fraternal", "amor filial", "caridad", "amor hermanable", entre otros. También se encuentra en Rm 12, 10, 1 Tes 4, 9 y 2 Pe 1, 7. Es una palabra femenina que implica un amor a la projimidad (sean hombres o mujeres), pero, como la palabra "amor" está tan falseada, podríamos traducir como un compromiso que nace de las entrañas por la otredad, ${ }^{4}$ para poner en palabras modernas la intencionalidad del autor. Esta filadelfía es el marco interpretativo para las vivencias que explica a continuación. Además, podemos recuperar este mandamiento de Hebreos: e filadefía menéto, pues la última palabra de esta oración tiene voz imperativa (menéto), pero también continua, sería algo

4 Término filosófico incorporado por Emmanuel Lévinas para referirse a los diferentes, quienes no son de la propia cultura, religión, clase social, etc. La otredad participa también en la construcción de la propia identidad. 
así como: "permanezcan siempre en amor fraternal", mandamiento central para vivir la doctrina de la justicia.

La filadelfía es fundamental porque se expresa en:

- Vivir la hospitalidad ( $\mathrm{Hb} 13,2)$.

- $\quad$ Ocuparse de los prisioneros $(\mathrm{Hb} 13,3)$ como si estuvieran compartiendo esa misma suerte de falta de libertades.

- $\quad$ Preocuparse de quienes sufren corporalmente $(\mathrm{Hb} 13,3 b)$, poniéndose en su misma piel.

- Valorar las relaciones conyugales y no mancharlas ( $\mathrm{Hb} 13,4)$.

- Desapegarse del dinero por el peligro de reemplazar a Dios mismo $(\mathrm{Hb}$ 13, 5-6) citando a Dt 31, 6.

- Acordarse e imitar la fe de sus dirigentes religiosos ( $\mathrm{Hb} 13,7)$.

- Practicar un culto auténtico, sin dejarse engatusar por doctrinas extrañas $(\mathrm{Hb} 13,8-12)$.

- Salir de los espacios sagrados donde se encuentra la humillación cotidiana ( $\mathrm{Hb} 13,13-14)$.

- $\quad$ Reconocer que el mayor sacrificio agradable a Dios es hacerse el bien entre todos $(\mathrm{Hb} 13,16)$.

- $\quad$ Obedecer siempre a sus dirigentes, procurando su alegría y no sus lágrimas, porque ellos rinden cuentas a Dios por todos, es decir, es una dirigencia transparente $(\mathrm{Hb} 13,17-18)$ y dada a sus fieles.

Esta lista de deberes cristianos nace de la experiencia profunda de la filadelfía entre hermanos. No se trata de cumplir nada más una ley sin sentido. Es más bien una invitación a experimentar la filadelfía para que ella te oriente a vivir con compromiso comunitario. Es decir, como dice el versículo $\mathrm{Hb} 13,16$ : “No se olviden hacer el bien y ayudarse mutuamente, porque en tales sacrificios se complace Dios". Hacer el bien a la comunidad se constituye en el mejor sacrificio agradable a Dios. Un nuevo culto religioso que parte de las necesidades humanas y se eleva hacia Dios. Esta doble dimensión de la fe es indispensable para la vida cristiana.

Esta filadelfía tiene carácter universal, se la debe vivir en toda la comunidad cristiana, tanto las bases como su dirigencia. En muchas ocasiones, las autoridades eclesiales solo buscan el aplauso, los primeros lugares o el reconocimiento social. Esas actitudes no se alinean al mandato de permanecer en amor filial, mandamiento para toda la comunidad creyente, que comienza por quienes prestan el servicio sacerdotal y diaconal, y termina en toda la sociedad laica, contagiada por el espíritu filadélfico. 
En este contexto bíblico, existe un cristianismo naciente con una organicidad que exige la presencia de personas capacitadas que están al frente de esas comunidades, que hacen un servicio de diaconía; solo así se pudo perdurar en el tiempo. Pero esta dirigencia responde a las necesidades del pueblo, con transparencia y entrega a su servicio. Como el mismo texto señala, "se encuentran derramando lágrimas" ( $\mathrm{Hb} 5,7)$, viviendo las mismas condiciones adversas que el pueblo de Dios.

La cristología sacerdotal, entonces, es una figura literaria útil para su autor, que le permite dar un mensaje con sabiduría a la comunidad destinataria que posiblemente experimentaba un desánimo en su propia fe. Quizá vivía con duda por el origen de Jesús, quizá no coincidía con la esperanza mesiánica del judaísmo de la época o por el contexto político represivo prefería dejar a las comunidades cristianas.

También es posible que, como el culto estaba todavía en formación, era pertinente aportar a este para sugerir cuál sería el verdadero culto agradable a Dios basado en la filadelfía. El quiebre que las comunidades cristianas estaban experimentando con la religiosidad judaica es radical en la utopía de un nuevo culto al Dios vivo. El antiguo culto basado en la Ley y el sacerdocio levítico no respondía a las verdaderas necesidades de la comunidad y de Dios, por eso se debía hacer un parteaguas a partir de la fe en Jesús, el Cristo.

\section{Relectura en clave eclesial}

El pueblo latinoamericano está acostumbrado a unir vida y Biblia, siempre en un doble sentido de retroalimentación. Como indica el texto: "Pues, viva es la palabra de Dios y eficaz, y más cortante que espada alguna de dos filos" ( $\mathrm{Hb} 4,12)$. Apelando a esta eficacia, me permito su interpretación.

Hasta aquí se ha analizado la situación de la Iglesia heredada de Medellín y el texto de Hebreos, centrado en la salvación o liberación que solo es posible con Jesús, practicando una vida cristiana filadélfica y convocando a la unidad de todos los creyentes, sea este de las bases o sea dirigente, sean varones o mujeres. El énfasis de la responsabilidad por la comunidad cristiana la tiene la dirigencia capaz de compartir las situaciones más difíciles del pueblo y orientarlo hacia la esperanza que proviene de Dios.

Pues, a pesar de esta participación laical, a partir de los documentos del Concilio Vaticano II y la Conferencia de Medellín, la clericalidad, en su mayoría, se mantuvo a cierta distancia del pueblo sencillo y mirando con sospecha estos movimientos cristianos de base, si bien el documento hace un serio llamado a una 
pastoral popular: para la necesaria formación de estas comunidades, es preciso que se ponga en vigencia cuanto antes el diaconado permanente y se llame a una participación más activa en ellas a los religiosos, catequistas especialmente preparados y apóstoles seglares.

Finalmente, el Documento de Medellín se refiere a la pastoral de "élites" $\mathrm{y}$, en primer lugar, las define en varios campos (político, económico, educativo, académico, militar, sindical, cultural, etc.) y busca los mecanismos de llegar a ellos; sin embargo, le faltó hacer una autocrítica profunda a sus propias "élites religiosas" en las que se concentra el poder; la pastoral de élites también debe actuar ad intra. Solo con una mirada más integradora de la propia identidad de ser Iglesia es que podremos hacer una transformación. La Iglesia ve al mundo como un "otro"; le falta una identidad eclesial de ser "parte de esa otredad".

Medellín presenta dos apartados referidos a los "los laicos" (n. 10) y otro posterior dedicado a "los sacerdotes" (n. 11) en su tercer eje relativo a los miembros de la Iglesia. La lectura profunda de estas secciones demuestra la "corresponsabilidad" delegada a los laicos, pero sin que esto comprometa su participación activa dentro de espacios con poder de decisión. Por eso, cuando finaliza el documento, proponiendo una "pastoral de conjunto" (n. 15), no es suficiente para que todos los sujetos miembros de esta Iglesia nos involucremos en tal misión. El clero tiene reservas en "los primeros asientos" (Mc 12, 39).

Hubo una polarización del binomio laico-religioso. Solo en el discurso y en los documentos escritos se resaltaba la labor de laicos. En Lumen gentium, por ejemplo, el laicado debía apropiarse de la misión y evangelización eclesial, sin embargo, el clero jerárquico no cedió lo suficiente para provocar una misión encarnada de ambos sujetos, con las mismas condiciones.

El apoyo que compromete el Documento de Medellín a los laicos no ha sido honrado en el transcurso del tiempo por sus pastores y por el clero. Algunos laicos nos hemos formado en las instituciones teológicas y bíblicas, conscientes de que jamás podremos romper las estructuras jerárquicas de la Iglesia católica y de que no seremos reconocidos dentro de ella para asumir ningún cargo de liderazgo. Más aún si somos mujeres. Lo hicimos por vocación, por el placer de acercarnos más al Dios de la vida y por seguir dando respuestas cristianas al pueblo que muchas veces está "como ovejas sin pastor" (Mc 6, 34). Hemos hecho un trabajo de base con comunidades de fe, de diferentes formas, por lo que espero que en cada uno de esos esfuerzos haya "aleteado la Ruah divina", para encaminarnos hacia la verdadera salvación o liberación.

Si Jesús puede ser etiquetado como "sacerdote", no lo es con las características que este estamento tiene hoy en día. Podemos citar a sacerdotes que han 
encarnado verdaderamente por este sacerdocio de Cristo en nuestro continente; monseñor Oscar Arnulfo Romero, por poner un ejemplo. Una mayoría se quedó en una vocación vana y vacía de compromiso, mas otros osaron violentar a la feligresía y "escandalizar al pueblo sencillo" (Mt 18, 6) de formas muy variadas.

El clero no supo encarnar las realidades duras del pueblo de Dios como hizo la dirigencia del texto de Hebreos, sino que se mantuvo a cierta distancia del sufrimiento, y la "opción preferencial por los pobres" no tuvo la contundencia que demandaba el contexto. Resultó difícil poner los rostros de "los pobres" en estos cincuenta años y encarnar sus causas. Los criterios eran divergentes, entre quienes quieren mantener el clericalismo tradicional y la línea más progresiva que abre espacios de diálogo con sujetos que demandan también la salvación o liberación por parte de la Iglesia.

Hubo sujetos que reclamaron "preferencia" o, por lo menos atención, y que la Iglesia los pudo identificar: los indígenas, por ejemplo, pues los procesos de inculturación eclesial se incorporaron, luego la negritud también fue reconocida y escuchada en su clamor, la tierra y la ecoteología que se desarrolla también tuvo cabida en el quehacer pastoral eclesial. Sin embargo, las mujeres quedamos fuera, no hemos sido acogidas con esa "preferencia" que requería el contexto. Si nos urge esta, es porque por muchos siglos se nos negó la igualdad y la equidad, por eso estamos en desventaja frente a los varones que gozan de privilegios, en un continente donde una de cada tres mujeres es agredida con violencia, sin tomar en cuenta los altos índices de feminicidio. El patriarcado social deriva del patriarcado religioso, por eso urge indagar la genealogía religiosa y cultural de nuestro continente.

La Iglesia de nuestro continente debe examinar su rol en esta dura realidad, pues hubo algunas voces que se unieron a nuestras demandas, pero la mayoría las ignoró y pasaron de largo en la historia. Esas formas patriarcales y violentas también existen dentro de nuestra Iglesia cuando se nos relega a la servidumbre, ${ }^{5}$ cuando en las liturgias se nos invisibiliza pues todo el lenguaje es masculino, cuando nos ponen techos de cristal en las pastorales parroquiales, se nos niega el derecho de ser también guías por el solo hecho de ser mujeres, así tengamos formación teológica. Ivone Gebara, teóloga brasileña, en la Universidad Pontificia Comillas, el 1 de octubre de 2018, afirmó que "la Iglesia es patriarcal y corre el riesgo de perder a las mujeres que piensan". Existen muchas mujeres conformes con este

5 El papa Francisco en marzo de 2018 afirma: “Me preocupa que el papel de la mujer sea más de servidumbre que de servicio". 
sistema eclesial, ellas son incapaces de identificar la violencia simbólica, ${ }^{6}$ mas quienes hemos desarrollado un sentido crítico procuramos cambios hacia una justicia de género.

\section{Como posible conclusión: la propuesta eclesial y el discipulado de iguales}

Ojalá tuviera la fórmula diligente para provocar una profunda conversión de esta Iglesia clericalizada que sobrevive en tiempos de laicidad; no la tengo. Solo les puedo proponer algunas líneas de acción que quizá todos conocemos, mas no nos atrevemos a llevarlas a la praxis. En primer lugar, la Iglesia, como Pueblo del Dios vivo, debe recuperar el mandamiento de Hebreos "permanezcan siempre en amor fraternal". Esto implica revisar nuestras querencias, nuestras fraternidades, nuestra filadelfía, pues, si ellas radican en el Dios de la vida, a la vez son abiertas a la otredad, y con desapego al poder quiere decir que estamos en el camino.

La propuesta implica hacer un manifiesto eclesial aquí y ahora, desde este conjunto de organizaciones representativas de nuestro continente dirigido al Vaticano y al papa Francisco, que exponga, en primer lugar, la inconformidad que tenemos respecto de las estructuras eclesiales tal como están ahora, abordando los temas más sensibles que el clero todavía no se atreve a debatir, aunque esto implique revisar dogmas o tradiciones que provocan la diáspora lenta y continua de la feligresía católica. En segundo lugar, que proponga reformas epistemológicas hacia una nueva Iglesia más laica, más plural, más inclusiva, más filadélfica.

Tenemos la gran oportunidad de volver a ser una Iglesia profética latinoamericana y caribeña, que haga una lectura real del patriarcado eclesial y proponga la conversión que nace en las entrañas no solo de las mujeres, sino también de todo cuanto varón sea consciente de sus privilegios y quiera emprender caminos de igualdad y equidad. La idea de "revisar el Magisterio y su tradición" significa relativizar ciertas exigencias del sacerdocio actual. Por ejemplo, debería ser temporal, es decir, no un sacerdocio de por vida, sino mientras se esté en disponibilidad del Reino para ejercer este servicio; percibo que no se pueden seguir

6 Concepto acuñado por Pierre Bourdieu en la década de 1970. Se refiere a una violencia que se ejerce a través de patrones esteriotipados, mensajes, valores, íconos o signos que transmiten y reproducen dominación, desigualdad y discriminación en las relaciones sociales, y naturalizan la subordinación de la mujer en la sociedad. Implica una reproducción encubierta y sistemática, difícil de distinguir y percibir. 
haciendo votos perpetuos cuando el destino es tan incierto. Si el sacerdocio también debe estar inmerso en las realidades temporales y seglares, será consciente de las fragilidades humanas. Los votos deben ser temporales y amigables con las novedades del mundo, porque ahí también está Dios actuando.

El celibato obligatorio es un sinsentido en la actualidad. Son los resquicios de una Iglesia que todavía cree que la sexualidad y su ejercicio son pecado, o se ha quedado anclada en una realidad espiritual anacrónica de nuestros tiempos. La creación de los seres humanos por parte de Dios es integral. No podemos continuar en un mundo "secular" espiritualizando el mensaje de Dios y condenando sus realidades corporales como, todavía, impuras. La opción de su dirigencia eclesial no debería verse privada de ejercitarla si así lo deseare; honrando la dignidad humana, todo nuestro cuerpo es templo del Espíritu (2 Cor 3, 16-17).

Si bien el sacerdocio no es el sueño de todas las mujeres, para quienes lo sueñan debería ser posible, porque las mujeres hemos demostrado intuición teológica desde nuestra maestra María de Magdala, al ser la primera en anunciar la resurrección de Jesús. Ahí encontramos una voz profética, capaz de dar aliento a una comunidad sumida en el sufrimiento de la muerte. Hebreos hace una propuesta radical en cuanto a un sacerdocio nuevo y vivificador que hoy pocos asumen. La novedad de un "sacerdocio universal" de Hebreos, a partir de Cristo, ha sido ignorado, pues dentro de la Iglesia han guardado una respetable distancia entre el sacerdocio consagrado y el común, el que tenemos todos a partir de nuestro bautismo.

Las mujeres en el cristianismo en general estamos proponiendo relecturas bíblicas, replanteamiento sobre su organicidad, una perspectiva integral de las personas, rupturas epistemológicas; en síntesis, ¡descolonización y despatriarcalización ya! Las mujeres de la Iglesia están "hartas de rezar , limpiar y callar" y han presentado a la Pontificia Comisión para América Latina (organismo del Vaticano que se ocupa del nuevo continente) una solicitud para el papa Francisco, a fin de que aborde la cuestión de las mujeres en un nuevo sínodo. Por su parte, Francisco se comprometió a estudiar la propuesta. Esperemos que la Ruah derrame toda su sabiduría en este proceso justo y urgente.

El discipulado de iguales que propone Elisabeth Schussler Fiorenza plantea la participación de todos en condiciones democráticas de justicia de género, raza, clase social, colonialismo, que desmonte los sistemas de poder. Lo propone a partir de la praxis de Jesús, y cuenta con dos características que quiero resaltar:

- El discipulado de Jesús se forma en ambientes laicos, fuera de la institucionalidad religiosa; esta es una paradoja que debemos revisar en nuestro mundo laicista. 
- $\quad$ El discipulado de Jesús no fue estrictamente masculino y no solo consistía en repetir lo que enseñe el maestro, sino en la capacidad de renunciar a "sí mismo" y enfrentar el mismo destino de quien llevó las Buenas Nuevas a su pueblo.

Esta forma de seguimiento es una propuesta contracultural a las estructuras religiosas y políticas de su contexto, y fue posible materializar la propuesta. Hebreos es un escrito dirigido a una comunidad que vivía este discipulado, que sufría las consecuencias y el riesgo que implicaba el cambio del paradigma religioso. En el aquí y el ahora, debemos procurar una Iglesia que practique un discipulado de iguales, y esto significa, en primer lugar, la distribución del poder entendido como autoridad y como servicio entre todos; en segundo lugar, recrear una identidad eclesial laica, pues la Iglesia debe concebirse como si fuera parte de las sociedades posmodernas, en constante diálogo con todos, comprendiendo la pluralidad y la diversidad de hoy, adaptándose más oportunamente a los cambios del mundo; finalmente, las religiones también son relativas y dinámicas, solo la dignidad humana es absoluta.

También el texto de Hebreos nos permite releer la celebración de los cincuenta años del Documento de Medellín de 1968, el cual no ha sido lo suficientemente efectivo para abrir los espacios a los laicos. La Iglesia ha preferido mantener la dupla clérigo-laico con cautas distancias. Eso de la "corresponsabilidad laical" es solo una ficción discursiva de Benedicto XVI (2012). Ha faltado el coraje de plasmar en los documentos y en la práctica el liderazgo a los laicos en la evangelización que se planteaba. Los cambios se dieron, pero no fueron suficientes.

Hablando, específicamente, de las laicas dentro de las Iglesias, resultamos víctimas de una Iglesia patriarcal y misógina, alejada de la filadelfía que propone Hebreos, de ese amor hermanable. Hemos sido desplazadas a los últimos lugares y lo que exigimos ahora es simplemente justicia de género a través de un discipulado de iguales. La Iglesia no puede pasar de largo ante la ola de violencia que sufren las mujeres, violencia que se inicia dentro de algunas Iglesias, las cuales justifican como "voluntad de Dios" la naturaleza débil y secundaria de las mujeres frente a los varones. Las iglesias cristianas no pueden evadir su responsabilidad ante una realidad de muerte naturalizada para las mujeres.

Cuando los sacerdotes y pastores hacen un tipo de relecturas bíblicas fundamentalistas que justifican la subordinación de las mujeres, están glorificando desde sus ambones toda la violencia que a diario se despliega y denuncia en todos los países. Esta violencia avalada eclesial y socialmente goza de una impunidad cómplice y descarada de toda la sociedad. 
De ahí que no solo nos limitamos a denunciar esta violencia intraeclesial, esta violencia simbólica en lo religioso, sino que también queremos proponer cambios y lo hacemos sumándonos a la propuesta del discipulado de iguales; desde este sueño, queremos dar a conocer nuestra utopía de una Iglesia democrática para con todos sus miembros, de una Iglesia con puertas abiertas para todos y esencialmente filadélfica con los sujetos más violentados de hoy: las mujeres.

Personalmente, me sumo a esta propuesta de una comunidad de sujetos con plenos derechos y obligaciones, y la acojo de brazos abiertos, quizá porque soy mujer y requiero una comunidad discipular de iguales que promueva la salvación o liberación para todos. La llamada propia de cada discípulo tiene el mismo origen y estamos convocados a la misma misión: hacer realidad la Basilea de Dios. Las mujeres católicas ya no queremos ser la "voz que grita en el desierto" (Jn 1, 23), sino "la semilla que cae en tierra fértil" (Mt 13, 23). Esa tierra fértil será esta Iglesia aquí y ahora, la que se encuentra haciendo anamnesis de su caminata, reparando daños, saldando deudas y procurando el Reino de Dios para todo su pueblo.

\section{Referencias}

Benedicto XVI. (2012). Mensaje del santo padre Benedicto XVI al Foro Internacional de Acción Católica. Recuperado de https://w2.vatican.va/content/benedict-xvi/es/messages/pont-messages/2012/documents/hf_ben-xvi_mes_20120810_fiac.html

Consejo Episcopal Latinoamericano. (1968). Documento de Medellín. Recuperado de http://www.diocese-braga.pt/catequese/sim/biblioteca/publicacoes_online/91/ medellin.pdf

Hoppin, R. (2009). La carta de Priscila: encontrando el autor de la epístola a los Hebreos. California, Estados Unidos: Lost Coast Press.

Pablo VI. (1964). Lumen gentium. Recuperado de http://www.vatican.va/archive/hist councils/ii_vatican_council/documents/vat-ii_const_19641121_lumen-gentium_ sp.html

Manzi, M. (2005). Carta a los Hebreos. Bilbao, España: Desclée de Brouwer.

Martínez Cano, S. (2014). Mujeres desde el Vaticano II: memoria y esperanza. Navarra, España: Verbo Divino.

Schussler Fiorenza, E. (1989). En memoria de ella. Bilbao, España: Desclée de Brouwer.

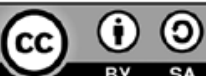

